\title{
VARIATIONS OF CALCANEAL FACETS ON TALUS IN NORTH KARNATAKA REGION
}

\author{
Sangeeta S Patil ${ }^{1}$, Archana N Kotli *2. \\ ${ }^{1}$ Assistant Professor, Department of Anatomy, Mahadevappa Rampure Medical College, Kalaburgi, \\ Karnataka, India. \\ ${ }^{* 2}$ Assistant Professor, Department of Anatomy, Mahadevappa Rampure Medical College, Kalaburgi, \\ Karnataka, India.
}

\section{ABSTRACT}

Background: The Talus is one of the important Tarsal bones. It carries the entire body weight and acts as a connecting link between the leg and the foot. Talus transmits weight from tibia to calcaneus. It's a peculiar bone because major part of it is covered by articular cartilage and it is devoid of any muscle attachments. Since it transmits large amount of weight many ligaments are attached to it. Various authors have studied on calcaneal articular facets of Talus and classified Talus based on it, very less data is available from North Karnataka region. Hence, the present study was carried out.

Materials and Methods: The present study was under taken on 200 dry adult human tali out of them 94 were right sided and 106 were left sided, obtained from bone library of Department of Anatomy, Mahadevappa Rampure Medical College, Kalaburgi and first year MBBS students of 2019- 2020 batch and were of unknown sex. The talus were looked for the number and type of calcaneal facets on its inferior surface and data recorded.

Results: Total of 200 tali (94 right sided and 106 left sided) of unknown sex were studied. Type II was the most common in occurrence in this region, total of 148 (74\%) were Type II, 69(73.40\%) rt and 79(74.52\%) It, then was Type I-41 (20.5\%), 20 (21.27\%) rt, 21(19.8\%) It. Type IV- 7(3.5\%), 03 (3.19\%) rt, 04 (3.7\%) on It, Type III - 03 (1.5\%), 01 (1.06) rt, 02 (1.88), the least in occurrence was Type V- 01 (0.53\%), 01(1.06\%) rt, nil on It side.

Conclusion: The tali can be classified on the basis of presence of number of calcaneal facets, which determines the stability. The most common type is Type II, even in this region as in many other part of India.

KEY WORDS: Calcaneal facets, Tali, articular facets, subtalar joint.

Corresponding Author: Dr. Archana. N. Kotli, Assistant Professor, Mahadevappa Rampure Medical College, Kalaburgi, Ph: 7204763456, 9900537779. E-Mail: drarchanahatti@gmail.com

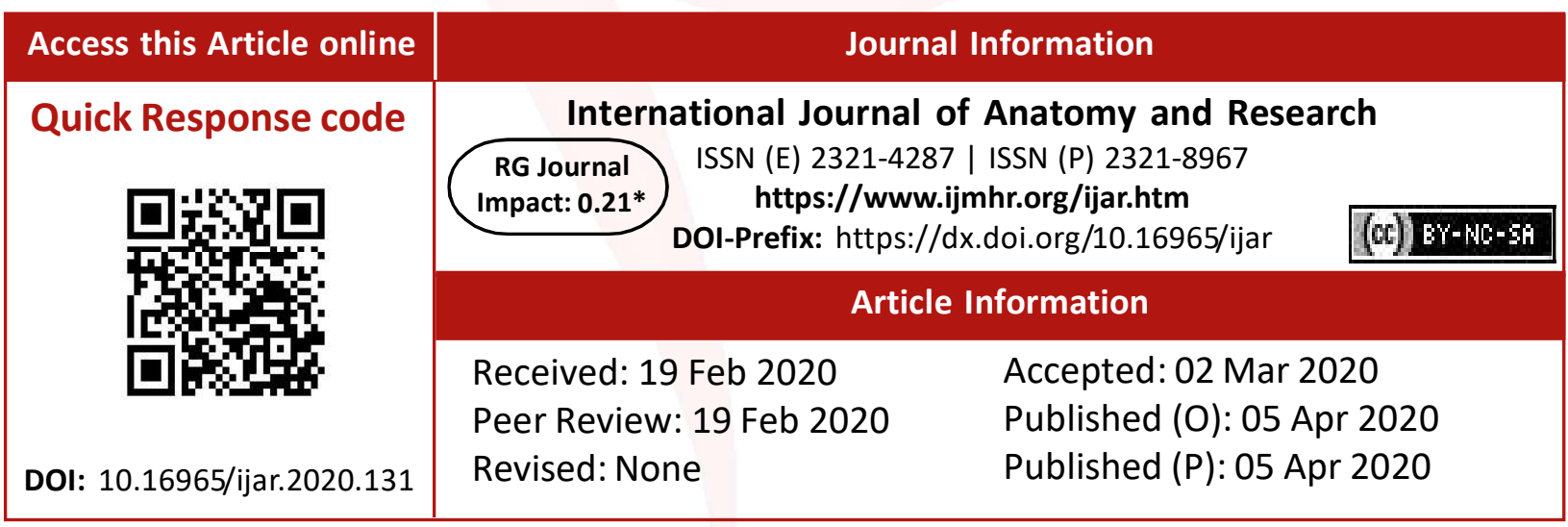

\section{INTRODUCTION}

The Talus transmits the weight of the body to all the other weight bearing bones of the foot. On the inferior surface the body presents a large posterior calcaneal articular surface separated from middle calcaneal facets by sulcus tali [1]. The bulk of the talus, the body, lies between the tibia above, calcaneum below and malleolus on each side, while the neck bears the rounded head which articulates with the navicular bone. No muscles or tendons are attached to the talus. The inferior surface bears a large oval concave posterior articular facet for the calcaneum separated by a groove from smaller middle articular facet for calcaneum. This facet on the under side of neck may be continuous with or separate from a smaller facet on the under side of the head, the anterior articular facet for the 
calcaneum [2].

Differences in incidence of different types of articular facets could be due to differences in gait, built and racial differences. Therefore, the present study was conducted on North Karnataka population to know the differences in articular facet, classify and co- relate with different authors.

Classification done on talus by Arora AK (3) was applied to the present study.

Type I: Anterior and middle facets completely fused.

Type II: Anterior and middle facets are separated by a ridge.

Type III: Anterior and middle facets are separated partly by a ridge and partly by groove.

Type IV: Anterior and middle facets are separated completely by a non articular groove.

Type V: Anterior, Middle and posterior facets fused. Sometimes ridge or groove might be present between anterior and middle.

In first four types, posterior facet is separate.

\section{MATERIALS AND METHODS}

The present study was under taken on 200 dry adult human tali out of them 94 were right sided and 106 were left sided, obtained from bone library of Department of Anatomy, Mahadevappa Rampure Medical College, Kalaburgi and first year MBBS students of 2019- 2020 batch and were of unknown sex. The talus were looked for the number and type of calcaneal facets on its inferior surface and data recorded. Damaged tali especially on the inferior aspect were excluded from the study. Photographs of different types of tali were taken along with other tali (Fig $1 \&$ 2).

\section{RESULTS}

Percentages of incidences of various types of calcanean facets were noted and classified. Total of 200 tali (94 right sided and 106 left sided) of unknown sex were studied. Type II was the most common in occurance in this region, total of 148 (74\%) were Type II, 69(73.40\%) rt and $79(74.52 \%) \mathrm{It}$, then was Type I- 41 (20.5\%), $20(21.27 \%)$ rt, 21(19.8\%) It. Type IV- 7(3.5\%), 03 (3.19\%) rt, 04 (3.7\%) on It, Type III - 03 (1.5\%), 01 (1.06) rt, 02 (1.88), the least in occurence was Type V- 01 (0.53\%), 01 (1.06\%) rt, nil on It side. Thus the study shows commonest Type of tali are Type II (ridge between anterior and middle facet) and least common are Type $\mathrm{V}$ (all articular surfaces fused). Table : 1 shows the results of the present study.

Fig. 1: Shows Tali studied

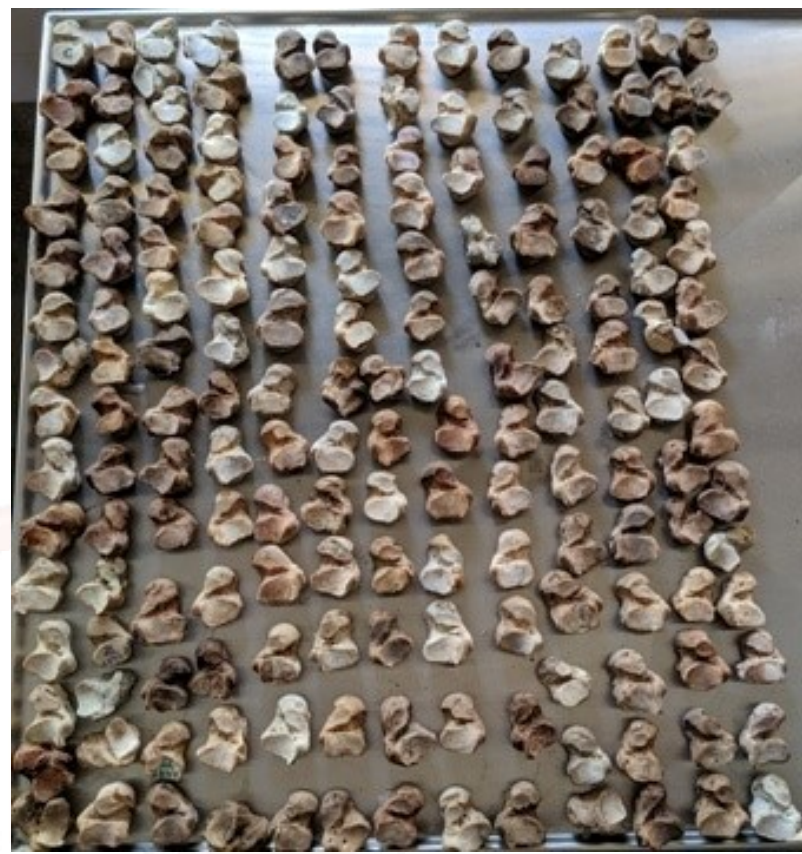

Fig. 2: Shows different types of Tali from study group.
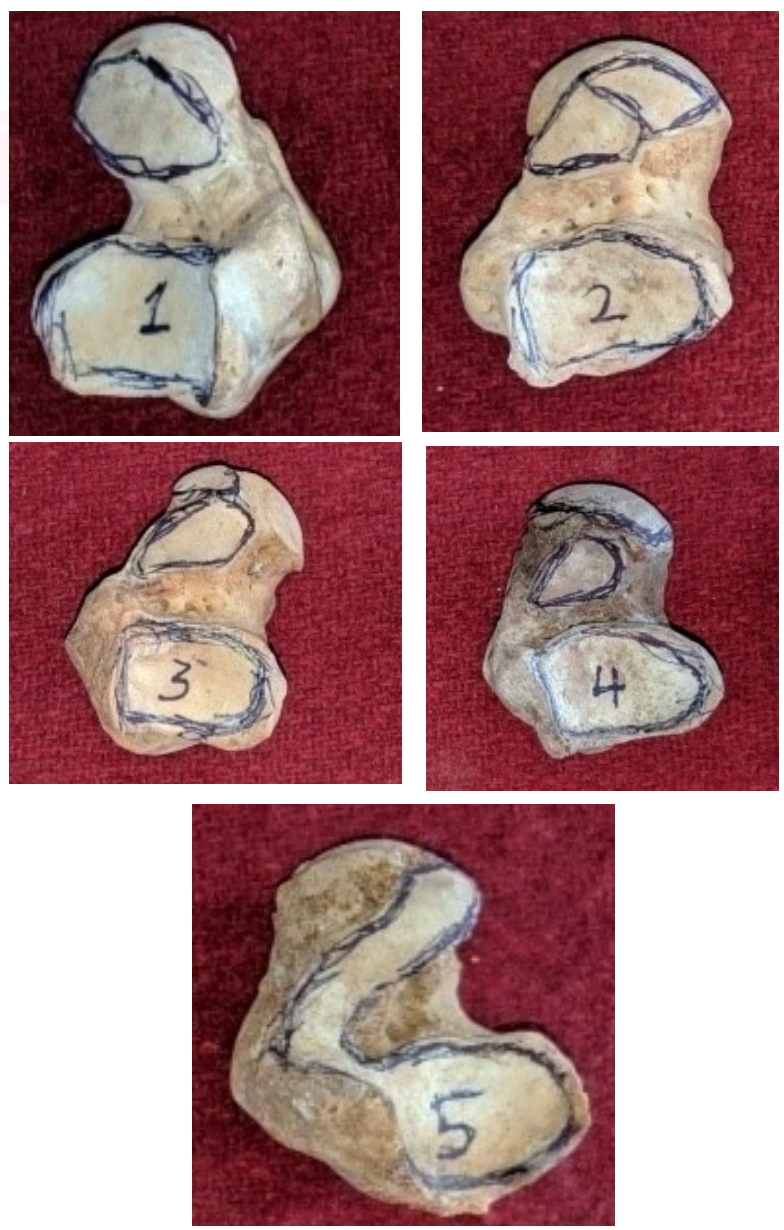
Table 1: Incidences of various of Types of calcaneal facets in present study.

\begin{tabular}{|c|c|c|c|}
\hline Type of Facet & Total Tali $\mathrm{n}=\mathbf{2 0 0}$ & Right side $\mathrm{n}=\mathbf{9 4}$ & Left side $\mathrm{n=106}$ \\
\hline Type I & $41(20.5 \%)$ & $20(21.27 \%)$ & $21(19.8 \%)$ \\
\hline Type II & $148(74 \%)$ & $69(73.40 \%)$ & $79(74.52 \%)$ \\
\hline Type III & $03(1.5 \%)$ & $01(1.06 \%)$ & $02(1.88 \%)$ \\
\hline Type IV & $07(3.5 \%)$ & $03(3.19 \%)$ & $04(3.7 \%)$ \\
\hline Type V & $01(0.53 \%)$ & $01(1.06 \%)$ & Nil \\
\hline
\end{tabular}

\section{DISCUSSION}

The Talus or astragalus consists of a body which articulates with tibia and fibula by its upper or trochlear surface, a forward projecting neck and a head which articulates with the navicular bone. The inferior surface of the body of talus rest upon calcaneus forming subtalar joints. The talus is covered entirely with cartilage of its numerous articular surfaces except for small surface of periosteum through which it receives its blood supply like other bones of tarsus, it usually develops from one centre of ossification. The bone is often site of tuberculosis [4]. It is also prone for avascular necrosis.

The subtalar joint is located in the foot between talus and calcaneus. Variations in the joint geometry include having either one, two or three facets. Increased facet surface area enables more joint mobility and restricted facet surface area restricts joint motion. In three facet arrangement, talus sits on stable articular tripod. A two facet configuration more mobile. The one facet configuration should be the most mobile since all facets have blended into one, providing maximum gliding area. A significant difference in joint mobility is expected between the joints with different numbers of articular facets [Jan Bruckner [5].
The study conducted on 76 Korean dry tali classified as Type A- three different articular facet, Type B- anterior and middle facets fused, but distinguished by a ridge and Type C-combined anterior and middle facet. Type B -60.5\% (similar to Type II of present study) was most common [B1- notch seperates 2 facets (Type III of present study), B2- without a definite notch( Type Il of present study)] B1 (28.9\%), B2 (31.6\%) Type C-30.3\% (Type I of present study) and Type A- 9.3\% was least common (Type IV of present study) [6].

Type II -74\% is more common type of tali in the present study, Arora AK- 78\% (3), Bilodi AK- 50\%(7), R Garg- 43.7\%, however second commonly occurring according to Kaur-24\%[9], Chandra-30\% [10] and Bhanu Sudha-32\% [11]. Type I most commonly found tali by the study of Kaur [9], Chandra[10], and Bhanu Sudha percentages of incidences are $45 \%, 42 \%$ and $52 \%$ respectively. The least common from the present study is Type V- $0.53 \%$. Studies done by different authors from different parts of India and their comparison to present study is shown in Table 2.

Table 2: Showing the percentage of incidences of various types of Tali from different part of India.

\begin{tabular}{|c|c|c|c|c|c|c|c|}
\hline SI.No & Study & Place & $\begin{array}{c}\text { Type I } \\
\%\end{array}$ & $\begin{array}{c}\text { Type II } \\
\%\end{array}$ & $\begin{array}{c}\text { Type III } \\
\%\end{array}$ & $\begin{array}{c}\text { Type IV } \\
\%\end{array}$ & $\begin{array}{c}\text { Type V } \\
\%\end{array}$ \\
\hline $\mathbf{1}$ & Present Study & North Karnataka & 20.5 & 74 & 1.5 & 3.5 & 0.53 \\
\hline $\mathbf{2}$ & Arora AK [3] & North Indian & 16 & 78 & 1 & 3 & 2 \\
\hline 3 & Bilodi AK [7] & Kolar, Karnataka & 10 & 50 & 16.66 & 5 & 8.41 \\
\hline $\mathbf{4}$ & R Garg et al [8] & Jaipur, Rajasthan & 39 & $43.70 \%$ & 6 & 5.3 & 6 \\
\hline $\mathbf{5}$ & Kaur et al [9] & North India & 45 & 24 & 9 & 5 & 17 \\
\hline $\mathbf{6}$ & Chandra [10] & Puduchery & 42 & 30 & 4 & 3 & 21 \\
\hline $\mathbf{7}$ & Bhanu Sudha et al [11] & Andhra Pradesh & 52 & 32 & 1 & 3.6 & 10.7 \\
\hline
\end{tabular}

\section{CONCLUSION}

The calcaneal articular facets of Talus are important as they are involved in formation of subtalar joint and determine the mobility and stability of the joint. Present study shows Type II facet being commonest similar to many other authors and Type $\mathrm{V}$ being the common. 


\section{ABBREVIATIONS}

rt- Right

It- Left.

\section{Conflicts of Interests: None}

\section{REFERENCES}

[1]. W. Henry Hollinshed and Cornelius Rosse. Leg and Foot. Text Book Of Anatomy. $4^{\text {th }}$ Ed. Harper \& Row Publishers, Inc. 1985. Pg 407.

[2]. R. D. Lockhart, G. F Hamilton and F. W. Fyfe. Tarsus. Anatomy of the Human Body. $1^{\text {st }}$ Ed. Faber \& Faber Limited, London. 1959. Pg 136.

[3]. Arora AK, Gupta SC, Gupta CD, Jeyasingh P. Variations in calcanean facets in Indian Tali. Anat Anz. 1979;146(4):377-80.

[4]. Barry J. Anson and Chester B. The Lower extremity, Ankle. Surgical Anatomy. $5^{\text {th }}$ Ed. W B Saunders Company/ Philadelphia London Toronto. 1971. Pg 1213.

[5]. Jan Bruckner: Variations in the Human Subtalar Joint. The Journal Of Orthopaedic And Sports Physical Therapy. 1987; Vol 8 (10): 489-94.

[6]. Ji Yong Lee, Min- Ho Jung, Jin Suk Lee, Byoung Young Choi, Byyong Pil Cho. Types of calcaneal articular facets of the Talus in Korean.Korean J Phys Anthropol. 2012; vol 25, No 4: pg 185-192.
[7]. Bilodi AK. Study of calcaneal articular facets in human tali, Kathmandu University Medical Journal. 2006; vol 4 No 1, Issue 13: 75-77.

.[8]. R Garg, S Babuta, K Mogra, R Parashar, S Shekhawat. Study of Variations in Pattern of Calcaneal Articular Facets in Human Tali in the Population of Rajasthan. People's Journal of scientific Research. July 2013; Vol 6( 2): 19- 23.

[9]. Kaur M, Kalsey G, Laxmi V. Morphological classification of Tali on the basis of calcanean articular facets. PB Journal of Orthopedics; 2011; 12 (1): 57- 60.

[10]. X. Chandra Philip and G Prabavathy. Study of anatomical variations of human tali based on their calcaneal articular facets. Research Journal of Pharmaceutical, Biological and chemical Sciences . 2014; 5(5): 1484- 1490.

[11].Bhanu Sudha, Parimala Namburu, H Kaavya, S Muralidhar Reddy. A Study Of Morphology Of Talus And Its Calcaneal Facets. International Journal Of Anatomy and Research. 2017;5(4.2):4570-74.

\author{
How to cite this article: \\ Sangeeta S Patil, Archana N Kotli. VARIATIONS OF CALCANEAL \\ FACETS ON TALUS IN NORTH KARNATAKA REGION. Int J Anat Res \\ 2020;8(2.1):7450-7453. DOI: 10.16965/ijar.2020.131
}

